\title{
Effect of propofol and isoflurane on gas exchange parameters following one-lung ventilation in thoracic surgery: a double-blinded randomized controlled clinical trial
}

Shima Sheybani ${ }^{1}$, Alireza Sharifian Attar ${ }^{2}$, Sogol Golshan ${ }^{3}$, Shadi Sheibani ${ }^{4}$, Majid Rajabian ${ }^{5}$

${ }^{1}$ M.D., Cardiac Anesthesiologist, Assistant Professor, Department of Anesthesiology, Faculty of Medicine, Mashhad University of Medical Sciences, Mashhad, Iran

${ }^{2}$ M.D., Anesthesiologist, Associate Professor, Department of Anesthesiology, Faculty of Medicine, Mashhad University of Medical Sciences, Mashhad, Iran

${ }^{3}$ M.D., Resident of Anesthesiology, Department of Anesthesiology, Mashhad University of Medical Sciences, Mashhad, Iran

${ }^{4}$ M.D., Internist, Mashhad, Iran

${ }^{5}$ Bachelor of science, Anesthetist Nurse, Department of Anesthesiology, Mashhad University of Medical Sciences, Mashhad, Iran

\section{Type of article: Original}

\begin{abstract}
Background: The use of anesthetic drugs with minimal inhibitory effects on the hypoxic pulmonary vasoconstriction (HPV) could have a decisive role in preventing the hypoxemia during one-lung ventilation (OLV).

Objective: The aim of this study was to compare the effects of propofol and isoflurane on the changes in gas exchange parameters following OLV in thoracic surgery.

Methods: This double-blinded randomized controlled clinical trial was conducted on patients who were candidates for elective right thoracotomy referred to the central operating room of Ghaem Hospital in Mashhad, Iran, during February 2016-2017. Patients with age range of 18 to 75 years, class I and II American Society of Anesthesiologists (ASA) and thoracotomy with OLV for pulmonary resection or cyst drainage were included. The patients were randomly allocated (1:1 ratio) into two groups of propofol $(\mathrm{P}, 50-100 \mu \mathrm{g} / \mathrm{kg} / \mathrm{min})$ and isoflurane (I, 1 minimum alveolar concentration (MAC) 1.1\%). Partial pressure of carbon dioxide (PaCO2), partial pressure of oxygen $(\mathrm{PaO} 2)$, end-tidal carbon dioxide $(\mathrm{ETCO} 2)$ and arterial oxygen saturation $(\mathrm{SPO} 2)$ were recorded before and 15 minutes after OLV and compared between the two groups. The comparison of the mean gas exchange parameters before and 15 minutes after OLV was performed using Mann-Whitney test in SPSS version 19 software. $\mathrm{P}<0.05$ was considered statistically significant.

Results: In this study, 122 patients with mean age of $59.4 \pm 14.1$ years (two groups of 61 ) were studied. Both groups were matched for age or gender. The two groups had no significant difference in the gas exchange parameters before the OLV. Only PaCO2 $(\mathrm{p}=0.001)$ and ETCO2 $(\mathrm{p}=0.001)$ were significantly higher in the propofol group after 15 minutes OLV than in the isoflurane group. However, $\mathrm{PaO} 2(\mathrm{p}=0.67), \mathrm{O} 2 \mathrm{Sat}(\mathrm{p}=0.333)$ and $\mathrm{PaCO} 2-\mathrm{ETCO} 2$ gradient $(\mathrm{p}=0.809)$ showed no significant difference between the two groups at this minute.

Conclusion: Based on the results of this study, the propofol or isoflurane selection seems to have no significant effect on the arterial oxygenation. On the other hand, isoflurane and propofol could be an appropriate anesthetic for thoracic surgery by normalizing the carbon dioxide gradient range during the OLV.

Clinical Trial Registration: The study was also registered at the Iranian Registry of Clinical Trials (IRCT2015123013159N8).

Funding: The study was financially supported by the Deputy of Research of Mashhad University of Medical Sciences (grant number: 940119).

Keywords: Hypoxemia, One-Lung Ventilation, Propofol, Isoflurane, Oxygenation

\section{Corresponding author:}

Associate Professor Dr. Alireza Sharifian Attar, Department of Anesthesiology, Faculty of Medicine, Mashhad University of Medical Sciences, Mashhad, Iran. Tel: +98.5138417402, Email: sharifiana@mums.ac.ir

Received: November 11, 2017, Accepted: January 25, 2018, Published: February 2018

iThenticate screening: January 21, 2018, English editing: February 12, 2018, Quality control: February 15, 2018

This article has been reviewed / commented by four experts

(C) 2018 The Authors. This is an open access article under the terms of the Creative Commons Attribution-NonCommercialNoDerivs License, which permits use and distribution in any medium, provided the original work is properly cited, the use is non-commercial and no modifications or adaptations are made.
\end{abstract}




\section{Introduction}

One-lung ventilation (OLV) means the mechanical separation of the two lungs in order to create ventilation conditions for a lung independently of another lung (1). Hypoxemia during OLV is one of the undesirable but unavoidable consequences in the management of anesthesia among patients undergoing thoracic surgery that occurs in 1 to $10 \%$ of patients in the presence of fraction of inspired oxygen (FIO2) $=100 \%(2,3)$. The degree of hypoxemia during OLV is mainly influenced by the increase in the shunt and dead space (4). In fact, pulmonary arteriovenous fistula due to the presence of unsaturated blood is the most important cause of hypoxemia during OLV; hypoxic pulmonary vasoconstriction (HPV) is the major physiological defense mechanism against shunting $(5,6)$. Based on this mechanism, pulmonary perfusion deviates from the unvented area to the ventilated area of the lung, and thus the unsaturated blood shunt is reduced and the hypoxemia is improved (5-7). Various factors such as temperature, acidity, airway pressure, patient position and cardiac outflow are effective on the HPV inhibitory effect $(8,9)$. On the other hand, anesthetics are among other key factors affecting the contraction of HPV. Therefore, the use of drugs with minimal inhibitory effects on this vital mechanism is of great importance $(10,11)$. The two main drug categories for the maintenance of anesthesia, including propofol (intravenous) and isoflurane (inhalational), are relatively new anesthetics that have rapid onset and offset due to low blood/gas partition coefficient and contextsensitive half-life. However, their effect on HPV and subsequently on partial pressures of oxygen (PaO2), carbon dioxide $(\mathrm{PaCO} 2)$, and end-tidal carbon dioxide (ETCO2) has not yet been well studied $(2,5,6$, 12). Although it seems that the vasoconstrictive effect of inhalational anesthetics can affect the protective role of HPV and may interfere with the oxygenation during the OLV, the recent studies on the effect of inhalational and intravenous anesthetics on $\mathrm{PaO} 2$ have revealed contradictory findings (5, 13 and 14). The majority of studies compared sevoflurane with propofol (12-17); and limited researches compared the effect of isoflurane with propofol (5, 18, 19). In three studies comparing the effects of propofol and isoflurane, although the findings from two studies (5, 20) found no difference in the effect of these two drugs, another study (19) revealed that isoflurane and desflurane reduced arterial oxygen pressure in animal models. Most of the studies merely reported $\mathrm{PaCO} 2$ as an index for the ventilation status, and very few studies have examined other indexes such as ETCO2 $(5,18-20)$. Therefore, it seems that there is a need to provide further evidence for comparing the effect of inhalational and intravenous anesthetics using varied parameters of the ventilation status within larger sample size. The aim of this study was to compare the effects of propofol and isoflurane on the changes in gas exchange parameters following OLV in the thoracic surgery.

\section{Material and Methods}

\subsection{Study design}

This parallel double-blinded randomized controlled clinical trial was conducted on patients who were candidates for elective right thoracotomy referred to the central operating room of Ghaem Hospital in Mashhad, Iran, during February 2016-2017.

\subsection{Participants}

Inclusion criteria were age range of 18 to 75 years, class I and II American Society of Anesthesiologists (ASA) and thoracotomy with OLV for pulmonary resection or cyst drainage. Primary exclusion criteria included liver dysfunction (Aspartate Aminotransferase (AST)> 40 and Alanine Aminotransferase (ALT) $>40$ ), ischemic or valvular heart disease (based on history taking, physical examination, ECG and echocardiography), end-stage chronic obstructive pulmonary disease, pathological lesions in the left lung (dependent lung) based on highresolution CT scan (HRCT) and pulmonary function test (PFT), and recent history of anesthesia. Secondary exclusion criteria were OLV duration less than 30 minutes, and ETCO2 higher than $45 \mathrm{mmHg}$ with respiratory rate of 12 breaths per minute at the onset of anesthesia and before one-lung ventilation.

\subsection{Sampling and allocation}

The sample size of the study, with two-tailed $\alpha$ error of $5 \%$ and $\beta$ error of $20 \%$, was calculated as 61 individuals for each group according to Sharifian et al. (5); based on PaO2 level of $84.01 \pm 20.67$ for Propofol and $79.66 \pm 17.04$ for Isoflurane. The patients were selected through simple random sampling from the primary statistical population. Then, the patients were randomly assigned to either propofol or isoflurane groups in a randomized allocation method based on a randomized allocation table with a 1:1 ratio.

\subsection{Data collection}

At the baseline, the weight, age and arterial oxygen saturation were recorded in the checklist. In all patients after pre-oxygenation, the anesthesia was induced by sodium thiopental $4 \mathrm{mg} / \mathrm{kg}$, sufentanil $0.2 \mu \mathrm{g} / \mathrm{kg}$ and atracurium 0.5 $\mathrm{mg} / \mathrm{kg}$. Then, a left-side double-lumen tube (MPI, Medicoplast GmbH Company) was placed for the patients. The 
proper intubation position was determined using auscultation and fiberoptic bronchoscopy. After changing the posture of the patients to the lateral decubitus, the correct intubation position was confirmed again with auscultation and fiberoptic bronchoscopy before starting the OLV. Ventilator settings were similar for all patients during twolung ventilation (TLV) and OLV, which were adjusted according to the instructions: tidal volume (VT) of $6 \mathrm{cc} / \mathrm{kg}$ based on ideal weight, respiratory rate of 12 breaths per minute, inhalation-to-exhalation ratio of one to two, and FIO2 of one (to create ETCO2 between 35 and $45 \mathrm{mmHg}$ ). The peep was adjusted to $5 \mathrm{mmHg}$ during OLV for all patients. During the surgery, if the ETCO2 reached more than $50 \mathrm{mmHg}$, respiratory rates would be increased to reduce the ETCO2 levels. The patients were then assigned to either propofol (Group P) or isoflurane (Group I) groups, and the intervention was performed on the basis of a pre-specified protocol for each patient. The amount of liquid deficits was offset by $0.5 \mathrm{cc} / \mathrm{kg}$ of normal saline or lactate ringer per hour of fasting before anesthesia induction. In this study, an electrocardiogram was used to monitor the patients. The ETCO2 levels were determined with the side stream capnography (Sadat Co., Iran), the SPO2 with pulse oximetry, invasive arterial pressure with radial artery catheterization (IBP), and anesthetic depth monitoring with BIS. The patients experienced ABG to determine the $\mathrm{PaCO} 2$ and the $\mathrm{PaO} 2$ in stage 2. The first stage (T0) was before the OLV, that is, within a minute after the onset of anesthesia and during the TLV, and the second stage (T15) was performed fifteen minutes after the OLV. In addition, the SPO2 and ETCO2 values were recorded on checklists at similar times of T0 and T15, but they were monitored continuously during the surgery. If the SPO2 reached $90 \%$ or less, the ABG was immediately taken and the TLV was re-established. This ABG sample was considered as the lowest SPO2 of the patient and no more blood samples were taken for the study. The ABG was determined using the GEM premier 3000 device (WERFEN Company, Spain).

\subsection{Interventions, blinding}

In Group P, the propofol was administered at a dose of $50-100 \mu \mathrm{g} / \mathrm{kg} / \mathrm{min}$ for the maintenance of anesthesia combined with $0.01 \mu \mathrm{g} / \mathrm{kg} / \mathrm{min}$ sufentanil infusion after the intubation. In Group I, 1 minimum alveolar concentration (MAC) $1.1 \%$ isoflurane was prescribed for the maintenance of anesthesia along with $0.01 \mu \mathrm{g} / \mathrm{kg}$ sufentanil infusion after the intubation. The maintenance of general anesthesia was set for each patient based on $20 \%$ of allowable heart rate changes and mean arterial pressure (MAP) as the BIS (anesthetic depth monitoring) was kept between 40 and 60 during surgery. This study was conducted in a double-blind manner, so that the patient and anesthetist who completed the checklist were unaware of the type of intervention. The envelope containing the code and the type of drug was pre-prepared by an anesthetist of the faculty member and given to a nurse anesthetist as encoded.

\subsection{Outcomes}

The first outcome was to determine the mean ETCO2 within the first 10 minutes of anesthesia during the TLV (T0) and 15 minutes after the OLV (T15) between the groups. The second outcome was the mean PaCO2 at the times of $\mathrm{T} 0$ and $\mathrm{T} 15$ between the groups. The third outcome was the $\mathrm{ETCO} 2-\mathrm{PaO} 2$ gradient at the mentioned times between the groups.

\subsection{Statistical analysis}

Data were analyzed for the normal distribution using one-sample Lilliefors corrected Kolmogorov-Smirnov test. Regarding the non-normal distribution of $\mathrm{PaCO} 2, \mathrm{ETCO} 2, \mathrm{PaO} 2, \mathrm{O} 2 \mathrm{Sat}$ and $\mathrm{PaCO} 2-\mathrm{ETCO} 2$ gradient in this study, the mean of these parameters was compared before OLV and 15 minutes after OLV using the Mann-Whitney test. Pearson's chi-square was applied to analyze the frequency distribution of gender between the two groups. The mean age of the two groups was compared using independent t-test. Fisher's exact test was used in cases where more than $20 \%$ of the expected frequencies were less than 5 (Cochran). The statistical software used in this study was IBM SPSS Statistics for Windows (Version 19.0, Armonk, NY: IBM Corp), and the significance level in all tests was considered to be less than $5 \%$.

\subsection{Ethical considerations}

The Ethics Committee of Mashhad University of Medical Sciences approved this research project with the code of 940119 (Code of Ethics: IR.MUMS.FM.REC.1394.372). The research objectives were fully explained for each patient. The patients completed informed consent before entering the study and they participated in this study voluntary. The information of all patients was kept completely confidential until the end of the study and encoded into statistical software. The patients were completely supported by the researchers in the event of any related complication during the study. The participants were free to leave the research at any phase of the study. The study was also registered at the Iranian Registry of Clinical Trials (IRCT2015123013159N8). 


\section{Results}

\subsection{Baseline characteristics}

The present study was performed on 122 patients (60 males, 62 females) with the mean age of $59.4 \pm 14.1$ (Figure 1). There was no significant difference between the two groups in terms of the mean age (Group P vs. Group I: $59.2 \pm 16.9$ vs. $59.97 \pm 12.0$ years: $\mathrm{p}=0.895)$. The frequency distribution of gender was also homogeneous between the two groups (Group P vs. Group I: 33/28 vs. 29/32: male / female: p=0.469).

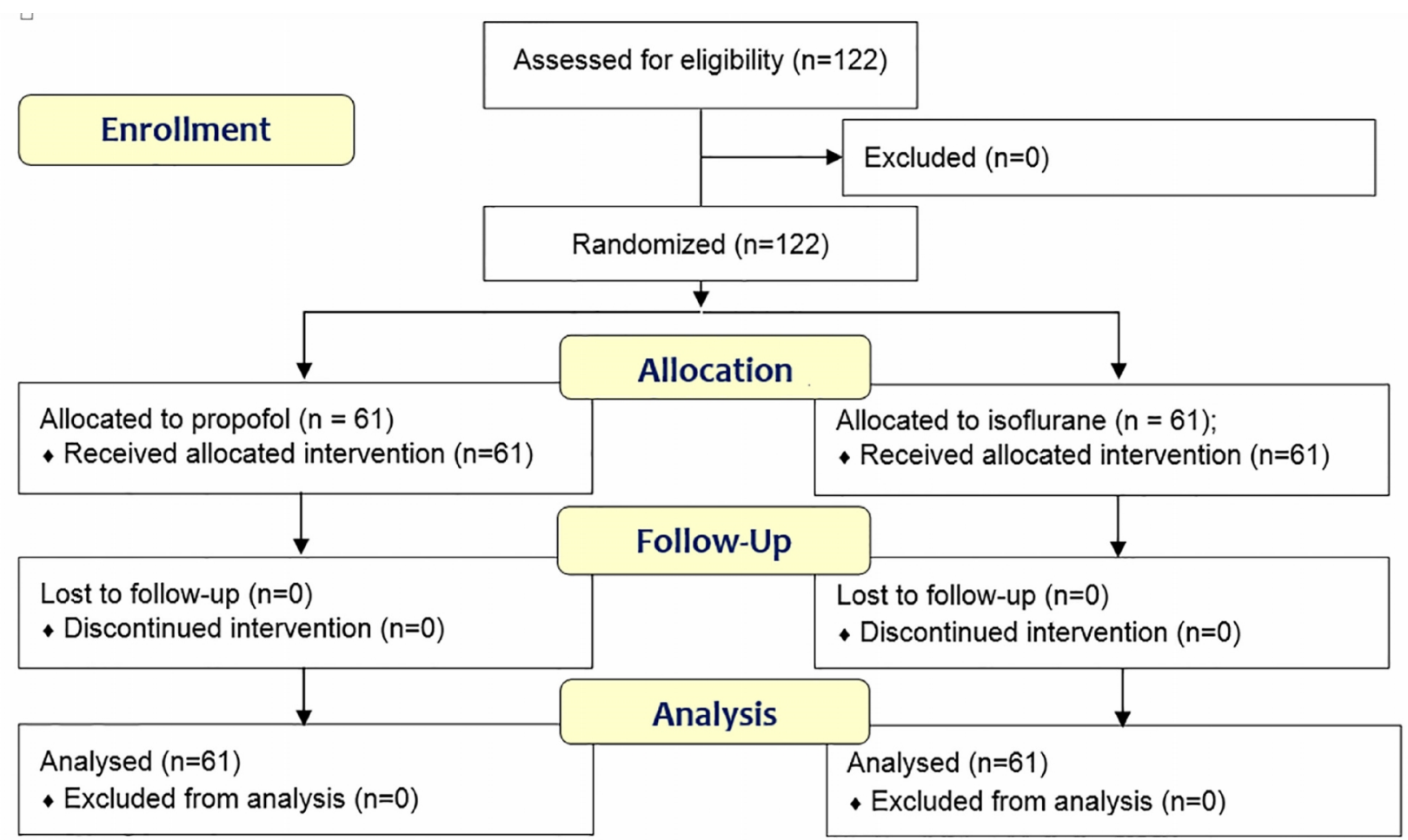

Figure 1. Follow-up diagram of patients (According to consort statement)

Table 1. Comparison of $\mathrm{PaCO} 2, \mathrm{ETCO} 2, \mathrm{PaO} 2, \mathrm{O} 2 \mathrm{Sat}$ and $\mathrm{PaCO} 2-\mathrm{ETCO} 2$ gradient before OLV (T0) and 15 minutes after OLV (T15) in two groups of propofol and isoflurane.

\begin{tabular}{|l|l|l|l|l|}
\hline Variable, unit & Interval to OLV & $\begin{array}{l}\text { Propofol group } \\
(\mathrm{n}=61)\end{array}$ & $\begin{array}{l}\text { Isoflurane group } \\
(\mathrm{n}=61)\end{array}$ & $\mathrm{p}$-value \\
\hline \multirow{3}{*}{$\mathrm{PaCO} 2, \mathrm{mmHg}, \mathrm{Mean} \pm \mathrm{SD}$} & Before OLV (T0) & $40.3 \pm 5.7$ & $40.2 \pm 4.6$ & 0.990 \\
\cline { 2 - 5 } & After 15 minutes (T15) & $41.7 \pm 7.6$ & $36.1 \pm 7.1$ & 0.001 \\
\cline { 2 - 5 } & Mean difference in T0-T15 & $0.4 \pm 8.4$ & $4.3 \pm 7.8$ & 0.002 \\
\hline \multirow{3}{*}{ ETCO2, mmHg, Mean \pm SD } & Before OLV (T0) & $30.0 \pm 5.3$ & $28.3 \pm 5.4$ & 0.076 \\
\cline { 2 - 5 } & After 15 minutes (T15) & $36.7 \pm 4.8$ & $31.5 \pm 4.2$ & 0.001 \\
\cline { 2 - 5 } & Mean difference in T0-T15 & $6.6 \pm 5.4$ & $3.2 \pm 3.6$ & 0.001 \\
\hline \multirow{3}{*}{$\mathrm{PaO} 2, \mathrm{mmHg}$, Mean $\pm \mathrm{SD}$} & Before OLV (T0) & $110.0 \pm 32.0$ & $111.2 \pm 36.7$ & 0.900 \\
\cline { 2 - 5 } & After 15 minutes (T15) & $151.7 \pm 63.2$ & $145.1 \pm 50.4$ & 0.627 \\
\cline { 2 - 5 } & Mean difference in T0-T15 & $44.4 \pm 61.0$ & $35.3 \pm 57.3$ & 0.426 \\
\hline \multirow{3}{*}{ O2Sat, mmHg, Mean $\pm \mathrm{SD}$} & Before OLV (T0) & $96.3 \pm 2.2$ & $96.4 \pm 2.0$ & 0.954 \\
\cline { 2 - 5 } & After 15 minutes (T15) & $97.1 \pm 1.6$ & $97.3 \pm 1.2$ & 0.333 \\
\cline { 2 - 5 } & Mean difference in T0-T15 & $0.7 \pm 2.5$ & $0.9 \pm 2.4$ & 0.613 \\
\hline \multirow{2}{*}{$\begin{array}{l}\text { PaCO2-ETCO2 Gradient, } \\
\text { mmHg, Mean } \pm S D\end{array}$} & Before OLV (T0) & $-9.9 \pm 7.2$ & $-11.8 \pm 6.3$ & 0.138 \\
\cline { 2 - 5 } & After 15 minutes (T15) & $-4.2 \pm 6.7$ & $-4.5 \pm 8.0$ & 0.809 \\
\cline { 2 - 4 } & Mean difference in T0-T15 & $5.8 \pm 9.1$ & $7.2 \pm 7.7$ & 0.379 \\
\hline
\end{tabular}

$\mathrm{PaCO} 2$ : partial pressure of carbon dioxide; $\mathrm{ETCO} 2$ : end-tidal carbon dioxide; $\mathrm{PaO} 2$ : partial pressure of oxygen 


\subsection{Outcomes}

Based on the results, the mean $\mathrm{PaCO} 2, \mathrm{ETCO} 2, \mathrm{PaO} 2$, O2Sat and $\mathrm{PaCO} 2-\mathrm{ETCO} 2$ gradient before OLV (T0) showed no significant difference between the propofol and isoflurane groups (Table 1). Only $\mathrm{PaCO} 2(\mathrm{p}=0.001)$ and ETCO2 ( $\mathrm{p}=0.001)$ were significantly higher in the propofol group after 15 minutes OLV than in the isoflurane group. However, $\mathrm{PaO} 2(\mathrm{p}=0.67), \mathrm{O} 2 \mathrm{Sat}(\mathrm{p}=0.333)$ and $\mathrm{PaCO} 2-\mathrm{ETCO} 2$ gradient $(\mathrm{p}=0.809)$ revealed no significant difference between the two groups at this minute (Table 1). The analyses of the variations between 0 and 15 minutes showed that only ETCO2 and $\mathrm{PaCo} 2$ changes in the propofol group were significantly higher than the isoflurane group, while these changes were not significant in other variables (Table 1).

\section{Discussion}

This study aimed to compare the effect of propofol and isoflurane on the gas exchange parameters during OLV in thoracic surgery. The results showed that only ETCO2 and $\mathrm{PaCo} 2$ were significantly different between the two groups within 15 minutes after OLV. There were no significant differences between the two groups in $\mathrm{PaO} 2, \mathrm{O} 2 \mathrm{Sat}$ and $\mathrm{PaCO} 2-\mathrm{ETCO} 2$ gradient. In our study, decreased $\mathrm{PaCO} 2$ and increased ETCO2 occurred significantly 15 minutes after OLV in the isoflurane group compared to the propofol group, but both parameters were within the normal range of changes in $\mathrm{PaCO} 2$ and ETCO2 (30-45 $\mathrm{mmHg})$.

For ease of comparing our findings with other studies, we tried to search the literature comprehensively. Accordingly, less than 20 studies $(5,6,12-15,17,19,21-26)$ have studied the effects of inhaled gases such as isoflurane, desflurane and sevoflurane compared with propofol on the outcomes related to the gas exchange status of human or animal models of OLV. However, only three studies $(5,18,19)$ compared isoflurane with propofol. Since the effects of different inhaled anesthetics on ventilation are different, we limited the comparisons to those three studies, though only Reid (20) and Attar (5) have been studied on human specimens, and the study of Schwarzkopf (27) has been conducted on a swine model. Interestingly, isoflurane and propofol were compared with each other in terms of changes in $\mathrm{PaCO} 2$ and ETCO2 for the first time in our study, while other studies have only compared their effect on hemodynamic parameters and $\mathrm{PaO} 2$. However, in reviewing the common outcomes in our and other studies, we found that the one-lung ventilation showed no significant difference in $\mathrm{PaO} 2$ between the two groups after OLV in our study, similar to Attar (5). In the study of Attar (5), it was found that arterial oxygen pressure was $217.40 \pm 137.99$ within 5 minutes and $182.39 \pm 122.39$ within 10 minutes during the OLV in the propofol group and $118.90 \pm 168.78$ and $155.35 \pm 109.21$ at 5 and 10 minutes in the isoflurane group, respectively, nearly consistent with our study. Reid (20) also reported no difference between these two anesthetic interventions in the outcomes of hypoxemia during OLV-treated patients, in line with our findings. Nevertheless, the question is that what justification can be found for insignificant difference between the levels of $\mathrm{PaO} 2$ and O2sat after OLV in the two groups. Apparently, the main cause of the lack of difference can be attributed to pulmonary vasoconstriction, or shunt, or underlying illness of the patients (in terms of carbon dioxide exchange in the lungs), which did not develop a significant hypoxemia $(1,3,6$, and 11). In addition, the cardiac output reduces when using isoflurane with direct control of HPV by volatile anesthetics, so that HPV may appear to be unchanged and hypoxemia cannot be created $(5,11)$ though we did not study this issue well as hemodynamic changes were not the outcomes of our study. Our study also exhibited that the pressure gradient between the two groups did not differ significantly between the two groups after the OLV. It seems that several factors, including patient posture, sampling errors, and V/Q mismatch due to shunt or dead space, could have clear effects on the PaCO2-ETCO2 gradient $(1,6,8,15)$; as a result, we did not see any significant difference between the two groups for the pressure gradient. However, the issue that was best considered in our study was to measure the incidence of hypoxemia during the follow-up period, because the findings of a study by Cho (6) indicated that despite the patients undergoing anesthesia with desflurane and propofol, they were not significantly and clinically different in terms of $\mathrm{PaO} 2$ level within the first minutes after OLV; but the frequency of hypoxic attacks in the patients under anesthesia with propofol has been higher than propofol. Therefore, if the hypothesis is true that the incidence rate of hypoxia in the patients undergoing anesthesia with inhalable gases is greater than that of the propofol, then it will not be easy to talk about the same effect of isoflurane with propofol on $\mathrm{PaO} 2$ during OLV, because the occurrence of hypoxic attacks, even instantaneously, can affect the patient's final outcome, especially the brain cognitive behaviors of the patients. We tried to control this issue with the simultaneous monitoring of O2Sat, though there was no difference between the two groups in terms of O2Sat levels and variations.

There were two important findings in our study. Assuming that the isoflurane does not really differ with the propofol in the incidence of the hypoxia, the findings could be new clues to better judging the effects of the isoflurane on the ventilation status following the OLV compared to the propofol. In fact, these findings highlight remarkably the 
importance of our study compared to other previous researches because no similar project has been done about these outcomes so far. Our results reported that the $\mathrm{PaCO} 2$ reached about $42 \mathrm{mmHg}$ and $36 \mathrm{mmHg}$ from about $40 \mathrm{mmHg}$ after OLV, respectively, in the propofol and isoflurane groups, while a slight increase occurred in the $\mathrm{PaCO} 2$ in the propofol group; the isoflurane group showed a decrease in this index. On the other hand, the ETCO2 in both groups was increased, but the increase in the propofol group was significantly higher than the isoflurane group. According to these two findings statistically, it can be concluded that the propofol may cause more respiratory depression than the isoflurane. On the other hand, the isoflurane causes $\mathrm{PaCO} 2$ to be altered to a more alkalotic state than the propofol, which in turn can lead to pulmonary artery vasodilatation and thus improve the lung perfusion. The fact is that in our view, since these changes in levels were mostly within the normal range of variations in the ETCO2 and the $\mathrm{PaCO} 2$, and although these differences in levels are statistically significant, it is not clinically easy to defend their different function and better isoflurane performance. In our study, the patients with chronic obstructive pulmonary disease (COPD) were included in the study and the severe type was excluded. Since $100 \%$ FIO2 was used in our patients during anesthesia, according to Haldane, there is a potential increase in $\mathrm{CO} 2$ in the patients with more severe COPD. Therefore, the propofol group was more likely to have COPD severity than the isoflurane group. We believe that the criteria for selecting inhalational or intravenous anesthetics should not be based solely on the gas exchange parameters. For example, other studies compared the status of inflammatory reactions between these drug categories, though, their findings are also contradictory in this regard. For example, while one study (28) found the beneficial effects of propofol infusion compared with inhalational isoflurane in controlling oxidative stress, another study (26) uncovered the more prominent role of sevoflurane in suppressing inflammatory responses to propofol. In another study, it has been shown that sevoflurane had a higher protective role against ischemiareperfusion injury (IRI) following OLV in thoracic surgery compared to propofol (29). However, it is clear that the findings of this study alone are inadequate to compare the effects of these two drugs and their role on the status of ventilation during OLV, as further studies with larger sample sizes are needed in this regard. Additionally, different limitations should be considered in interpreting the findings of this study. For example, we did not measure pulmonary shunt fraction, perfusion, or pulmonary artery contraction in each lung isolated during surgery. This can justify the effects of the anesthetic drug on the pulmonary blood flow, intravenous shunt fraction or degree of V/Q mismatch. Hence, it can hardly be concluded that the anesthetic drugs have an effect on the role of HPV during OLV. Furthermore, we did not stabilize the dose of isoflurane, propofol or sufentanil, like other human studies, so our results do not reflect the effect of the doses of a certain anesthetic drug. In addition, we did not record the hemodynamic changes during the OLV as this issue leads to ambiguity in the interpretation of the effects of cardiac output on the HPV. In this study, we did not investigate patients for a long period and so we could not compare other clinical outcomes between the two groups. We also did not employ different assessors to measure, although all measurements took place with digital equipment. It is suggested that future studies should be carried out with larger sample size and simultaneous control of hemodynamic parameters as well as long-term follow-up of patients for other clinical outcomes.

\section{Conclusions}

According to our findings, the use of intravenous propofol or inhalational isoflurane as the agents for the maintenance of anesthesia, in spite of lacking different effects on the $\mathrm{PaO} 2$ during OLV could be effective on the $\mathrm{PaCO} 2$ and the ETCO2. However, propofol seems to be successfully used in chest surgeries as an alternative to halogenated inhalational anesthesia. The results showed that propofol and isoflurane had no significant effect on arterial oxygenation.

\section{Acknowledgments:}

This article has been adapted from research by a thesis on Anesthesiology Specialty written by Dr. Sogol Golshan (thesis number: T-4398). This study was fully sponsored by the Research Deputy at Mashhad University of Medical Sciences, Iran (grant number: 940119).

\section{Trial Registration:}

The trial was registered at the Iranian Registry of Clinical Trials (http://www.irct.ir) with the Irct ID: IRCT2015123013159N8

\section{Funding:}

This study was financially supported by the Deputy of Research of Mashhad University of Medical Sciences as a research project (Code: 940119) 


\section{Conflict of Interest:}

There is no conflict of interest to be declared.

\section{Authors' contributions:}

All authors contributed to this project and article equally. All authors read and approved the final manuscript.

\section{References:}

1) McGrath B, Tennuci C, Lee G. The History of One-Lung Anesthesia and the Double-Lumen Tube. Journal of anesthesia history. 2017; 3(3): 76-86. PMID: 28842155.

2) $\mathrm{Ng} \mathrm{A}$, Swanevelder J. Hypoxaemia during one-lung anaesthesia. Continuing Education in Anaesthesia Critical Care \& Pain. 2010; 10(4): 117-22. doi: 10.1093/bjaceaccp/mkq019.

3) Purohit A, Bhargava S, Mangal V, Parashar VK. Lung isolation, one-lung ventilation and hypoxaemia during lung isolation. Indian journal of anaesthesia. 2015; 59(9): 606-17. doi: 10.4103/0019-5049.165855. PMID: 26556920. PMCID: PMC4613408.

4) Karzai W, Schwarzkopf K. Hypoxemia during One-lung Ventilation Prediction, Prevention, and Treatment. The Journal of the American Society of Anesthesiologists. 2009; 110(6): 1402-11.

5) Sharifian Attar A, Tabari M, Rahnamazadeh M, Salehi M. A comparison of effects of propofol and isoflurane on arterial oxygenation pressure, mean arterial pressure and heart rate variations following onelung ventilation in thoracic surgeries. Iran Red Crescent Med J. 2014; 16(2): e15809. doi: 10.5812/ircmj.15809. PMID: 24719749, PMCID: PMC3965882.

6) Cho YJ, Kim TK, Hong DM, Seo JH, Bahk JH, Jeon Y. Effect of desflurane-remifentanil vs. Propofolremifentanil anesthesia on arterial oxygenation during one-lung ventilation for thoracoscopic surgery: a prospective randomized trial. BMC anesthesiology. 2017; 17(1): 9. doi: 10.1186/s12871-017-0302-x. PMID: 28100177 PMCID: PMC5242054.

7) Della Rocca G, Coccia C. Ventilatory management of one-lung ventilation. Minerva anestesiologica. 2011; 77(5): 534-6. PMID: 21540809.

8) Dunham-Snary KJ, Wu D, Sykes EA, Thakrar A, Parlow LR, Mewburn JD, et al. Hypoxic pulmonary vasoconstriction: from molecular mechanisms to medicine. CHEST. 2017; 151(1): 181-92. doi: 10.1016/j.chest.2016.09.001. PMID: 27645688, PMCID: PMC5310129.

9) Swenson ER. Hypoxic pulmonary vasoconstriction. High altitude medicine \& biology. 2013; 14(2): 10110. doi: 10.1089/ham.2013.1010. PMID: 23795729.

10) Lumb AB, Slinger P. Hypoxic Pulmonary VasoconstrictionPhysiology and Anesthetic Implications. Anesthesiology. 2015; 122(4): 932-46. doi: 10.1097/ALN.0000000000000569. PMID: 25587641.

11) Tarry D, Powell M. Hypoxic pulmonary vasoconstriction. BJA Education. 2017: mkw076.

12) Beck DH, Doepfmer UR, Sinemus C, Bloch A, Schenk MR, Kox WJ. Effects of sevoflurane and propofol on pulmonary shunt fraction during one-lung ventilation for thoracic surgery. Br J Anaesth. 2001; 86(1): 38-43. PMID: 11575407.

13) Iwata M, Inoue S, Kawaguchi M, Takahama M, Tojo T, Taniguchi S, et al. Jugular Bulb Venous Oxygen Saturation During One-Lung Ventilation Under Sevoflurane- or Propofol-Based Anesthesia for Lung Surgery. Journal of Cardiothoracic and Vascular Anesthesia. 2008; 22(1): 71-6.

14) Jin Y, Zhao X, Li H, Wang Z, Wang D. Effects of sevoflurane and propofol on the inflammatory response and pulmonary function of perioperative patients with one-lung ventilation. Experimental and therapeutic medicine. 2013; 6(3): 781-5. doi: 10.3892/etm.2013.1194. PMID: 24137265, PMCID: PMC3786802.

15) Karci A, Duru S, Hepağuşlar H, Çiftçi L, Yilmaz O. Comparison of the effect of sevoflurane and propofol on oxygenation during gradual transition to one-lung ventilation. Brazilian Journal of Anesthesiology. 2014; 64(2): 79-83.

16) Schwarzkopf K, Hueter L, Schreiber T, Preussler NP, Loeb V, Karzai W. Oxygenation during one-lung ventilation with propofol or sevoflurane. Middle East J Anaesthesiol. 2009; 20(3): 397-400. PMID: 19950733.

17) Pruszkowski O, Dalibon N, Moutafis M, Jugan E, Law-Koune JD, Laloe PA, et al. Effects of propofol vs sevoflurane on arterial oxygenation during one-lung ventilation. Br J Anaesth. 2007; 98(4): 539-44. doi: 10.1093/bja/aem039. PMID: 17347180.

18) Reid CW, Slinger PD, Lenis S. A comparison of the effects of propofol-alfentanil versus isoflurane anesthesia on arterial oxygenation during one-lung ventilation. J Cardiothorac Vasc Anesth. 1996; 10(7): 860-3. doi: 10.1016/S1053-0770(96)80046-2. PMID: 8969391. 
19) Schwarzkopf K, Schreiber T, Preussler NP, Gaser E, Huter L, Bauer R, et al. Lung perfusion, shunt fraction, and oxygenation during one-lung ventilation in pigs: the effects of desflurane, isoflurane, and propofol. J Cardiothorac Vasc Anesth. 2003; 17(1): 73-5. doi: 10.1053/jcan.2003.13. PMID: 12635064.

20) Reid CW, Slinger PD, Lenis S. A comparison of the effects of propofol-alfentanil versus isoflurane anesthesia on arterial oxygenation during one-lung ventilation. Journal of cardiothoracic and vascular anesthesia. 1996; 10(7): 860-3. doi: 10.1016/S1053-0770(96)80046-2.

21) Abe K, Mashimo T, Yoshiya I. Arterial Oxygenation and Shunt Fraction During One-Lung Ventilation: A Comparison of Isoflurane and Sevoflurane. Anesthesia \& Analgesia. 1998; 86(6): 1266-70. PMID: 00000539-199806000-00025.

22) Abe K, Shimizu T, Takashina M, Shiozaki H, Yoshiya I. The Effects of Propofol, Isoflurane, and Sevoflurane on Oxygenation and Shunt Fraction During One-Lung Ventilation. Anesth Analg. 1998; 87(5): 1164-9. PMID: 9806702.

23) Karzai W, Haberstroh J, Priebe HJ. Effects of desflurane and propofol on arterial oxygenation during onelung ventilation in the pig. Acta anaesthesiol Scand. 1998; 42(6): 648-52. doi: 10.1111/j.13996576.1998.tb05296.x. PMID: 9689269.

24) Pagel PS, Fu JL, Damask MC, Davis RF, Samuelson PN, Howie MB, et al. Desflurane and Isoflurane Produce Similar Alterations in Systemic and Pulmonary Hemodynamics and Arterial Oxygenation in Patients Undergoing One-Lung Ventilation During Thoracotomy. Anesth Analg. 1998; 87(4): 800-7. PMID: 9768773.

25) Wang JY, Russell GN, Page RD, Jackson M, Pennefather SH. Comparison of the effects of sevoflurane and isoflurane on arterial oxygenation during one lung ventilation. Br J Anaesth. 1998; 81(6): 850-3. doi: 10.1093/bja/81.6.850. PMID: 10211007.

26) Sugasawa Y, Yamaguchi K, Kumakura S, Murakami T, Suzuki K, Nagaoka I, et al. Effects of sevoflurane and propofol on pulmonary inflammatory responses during lung resection. Journal of Anesthesia. 2012; 26(1): 62-9. doi: 10.1007/s00540-011-1244-y. PMID: 21979104.

27) Schwarzkopf K, Hueter L, Schreiber T, Preussler N, Loeb V, Karzai W. Oxygenation during one-lung ventilation with propofol or sevoflurane. Middle East J Anaesthesiol. 2009; 20(3): 397-400. PMID: 19950733.

28) Huang $\mathrm{CH}$, Wang YP, Wu PY, Chien CT, Cheng YJ. Propofol infusion shortens and attenuates oxidative stress during one lung ventilation. Acta Anaesthesiologica Taiwanica. 2008; 46(4): 160-5. doi: 10.1016/S1875-4597(09)60003-5.

29) Erturk E, Topaloglu S, Dohman D, Kutanis D, Beşir A, Demirci Y, et al. The Comparison of the Effects of Sevoflurane Inhalation Anesthesia and Intravenous Propofol Anesthesia on Oxidative Stress in One Lung Ventilation. Biomed Res Int. 2014; 2014: 360936. doi: 10.1155/2014/360936. PMID: 24527444, PMCID: PMC3909970. 